\title{
Diga-me com quem moras que eu te direi quem és: oscilações na captação de indígenas nos censos demográficos brasileiros
}

\author{
Marden Campos*
}

Os censos demográficos são uma importante fonte de informações sobre as condições de vida dos povos indígenas no Brasil. Diferentes explicações têm sido dadas para as variações observadas nos volumes de indígenas captados entre os censos. Os motivos para tais oscilações ancoram-se em análises da dinâmica demográfica dessas populações, assim como na influência dos processos de reconhecimento identitário e autodeterminação nos totais enumerados nas pesquisas. Desconhecem-se, contudo, estudos que investiguem o impacto das metodologias de coleta do censo sobre os resultados encontrados para a população indígena. 0 presente ensaio analisa os resultados dos últimos censos nacionais do Brasil para os indígenas segundo a composição de seus domicílios por cor ou raça dos moradores, assim como por região de residência e localização rural ou urbana dos mesmos. As análises indicam que alterações no formato de realização de entrevistas observadas nos últimos dois censos demográficos possivelmente tiveram impacto no perfil domiciliar dos indígenas captados e, consequentemente, no volume de indígenas recenseados no país. Esse impacto teria contribuído, inclusive, para uma redução daqueles que residiam nas áreas urbanas do país.

Palavras-chave: Indígenas. Censo demográfico. Brasil. Questionários.

\footnotetext{
* Universidade Federal de Minas Gerais (UFMG), Belo Horizonte-MG, Brasil (mardencampos@gmail.com; https://orcid. org/0000-0002-7397-5453).
} 


\section{Introdução}

Os censos demográficos são uma fonte de informações importante para estudos das populações indígenas do Brasil, tendo sido utilizados de forma crescente após a inserção da categoria "indígena" como opção de reposta da pergunta de cor ou raça desde o Censo Demográfico de 1991 (CAMPOS, 2017; LONGO; FERREIRA; AZEVEDO, 2016; PEREIRA, 2016; WONG, 2016).

Diferentes fatores têm sido apontados para explicar as variações dos volumes de indígenas captados pelos diferentes censos, assim como oscilações em sua distribuição espacial. Esses estudos concentram-se em análises da dinâmica demográfica dessas populações, assim como na influência dos processos de reconhecimento identitário e autodeterminação nos totais de população.

Existem diversos trabalhos que analisam o impacto dos processos de reconhecimento identitário nas variações da distribuição por outras categorias de cor ou raça da população brasileira (WOOD; CARVALHO, 1994; CARVALHO; WOOD; ANDRADE, 2004). No caso específico dos indígenas, Perz, Warrem e Kennedy (2008) mostraram os impactos de uma combinação de processo demográfico e mudança de identidades étnico-raciais no ressurgimento da população indígena brasileira. Tal fenômeno seria observado em diversos países latino-americanos. Segundo os autores, as políticas de reconhecimento identitário levaram os aparentemente não indígenas a reclassificarem sua etnia racial e se identificarem como indígenas. Tal fato decorreu da valorização das identidades indígenas, a partir de movimentos sociais, como meio de reafirmar reivindicações políticas e territoriais desses povos. Isso levou a uma alteração nos significados atribuídos às identidades indígenas, num processo de valorização que teve como consequência o aumento nas populações que se autodenominam indígenas em diferentes países do continente.

As análises quantitativas realizadas por Perz, Warrem e Kennedy (2008), com base nos resultados dos censos demográficos brasileiros, mostram que uma grande proporção da reclassificação étnica racial do país ocorreu em áreas urbanas, em que pesem os problemas indicados pelos autores na cobertura de indígenas residentes em áreas rurais no Censo Demográfico 2000.

Outros estudos indicam uma diminuição entre os Censos de 2000 e 2010 no volume de pessoas autodeclaradas indígenas que residiam em domicílios nos quais todos os moradores também eram indígenas (“unicolor”), principalmente nas áreas urbanas (MARINHO, 2015). Esse autor mostra diferenças marcantes entre os perfis de composição domiciliar segundo cor ou raça dos indígenas entre áreas urbanas e ruais no Brasil em 2010. Investigando a formação dos arranjos familiares de indígenas, Marinho (2015) observou que havia estreita associação entre a cor ou raça dos filhos e de seus pais, sobretudo das mães.

No caso dos resultados dos censos demográficos brasileiros referentes aos indígenas, desconhecem-se estudos que investiguem o impacto das metodologias de coleta dos censos sobre os resultados encontrados na coleta. Sem desconsiderar a importância dos impactos 
dos processos de reconhecimento étnico e da dinâmica demográfica própria das populações indígenas nos totais captados pelos censos demográficos, acredita-se que modificações nos procedimentos de coleta e desenho dos questionários podem interferir nos resultados divulgados, ainda mais em se tratando de grupos populacionais relativamente pequenos em relação ao tamanho da população brasileira.

0 presente ensaio analisa os resultados dos últimos censos nacionais do Brasil para os indígenas segundo a composição domiciliar em termos de cor ou raça dos moradores, por região geográfica de residência e situação de domicílio nos Censos de 2000 e 2010. Também são apresentadas as alterações na forma de realização das entrevistas que ocorreram entre esses dois censos. A partir de análises dos resultados do censo para indígenas, assim como de outros estudos que realizaram análises similares relativas a outras variáveis, apresentam-se evidências de associação entre as alterações na metodologia e a substancial modificação no perfil domiciliar dos indígenas segundo cor ou raça dos moradores.

Há estudos que demonstram que a captação da cor ou raça da população com base em entrevistas, por envolver um alto nível de subjetividade nas respostas, é bastante sensível ao formato do instrumento de investigação (MUNIZ, 2012). Nesse sentido, alterações em tais instrumentos podem provocar mudanças significativas nos resultados das pesquisas.

Com base nas análises realizadas, buscamos contribuir para a discussão sobre produção de indicadores de pertencimento étnico da população brasileira em um momento em que os preparativos para o Censo 2020 apontam para a expansão desse tipo de investigação, incluindo, por exemplo, a enumeração das comunidades quilombolas. Conclusões definitivas, entretanto, só poderão ser feitas após a realização do próximo censo, considerando-se que muitas das modificações introduzidas no Censo 2010, que acreditamos estarem relacionadas à captação dos indígenas, como o desenho dos questionários, tendem a se repetir na próxima coleta, fornecendo condições de melhor avaliar a hipótese aqui levantada.

\section{Os censos e as populações indígenas}

Apesar de muitos indígenas viverem nas cidades brasileiras, ainda há pouca informação no Brasil sobre esses grupos populacionais, comparativamente ao conhecimento produzido sobre os que vivem em terras indígenas ou ambientes rurais. Poucas são as áreas urbanas cobertas por estudos detalhados (MAGNANI; ANDRADE, 2013; NUNES, 2010). Os dados dos censos são importantes para fornecer informações sobre os indígenas que vivem nas cidades, sendo a única fonte de dados para essas áreas no conjunto do país.

0 estudo das condições de vida dos indígenas que vivem nas cidades brasileiras vem ganhando interesse recentemente devido às transformações no perfil e à diversidade étnica das áreas urbanas de nosso território (ARRUTI, 2013). Nesse sentido, têm surgido estudos de diversas naturezas relativos à presença indígena em ambientes urbanos (NUNES, 2010; 
HORTA, 2017; CAMPOS; DAMASCENO, 2019) e também sobre a migração dos indígenas para cidades (TEIXEIRA, 2008; TEIXEIRA; MAINBOURG; BRASIL, 2009).

Vale lembrar que, no Brasil, os temas da migração e da "urbanização" indígenas remetem à década de 1960, com destaque para o trabalho de Cardoso de Oliveira (1968) sobre a urbanização dos Terena e sua integração numa "sociedade de classes". Segundo o autor, a "urbanização" dos indígenas não implicava sua dissolução cultural e identitária, mas sim uma reprodução do "tribalismo" em um novo contexto e adaptado a ele. Os indígenas se integravam à sociedade de classes sem serem, contudo, completamente assimilados por ela.

A urbanização dos indígenas adquiriu ainda mais relevância após a divulgação dos resultados do Censo de 2000, quando a maioria dos indígenas do país foi captada em áreas urbanas. Porém, conforme Oliveira (2016), se foram os dados que trouxeram grandes novidades, ao mesmo tempo foram eles que nos colocaram diante dos maiores desafios interpretativos. 0 autor comenta que a divulgação dos resultados do Censo 2000 "instalou uma profunda perplexidade" na comunidade científica, ao mostrar o vertiginoso crescimento dos indígenas que moravam em cidades, grande parte das vezes em locais bastante afastados das principais regiões onde se localizam as terras indígenas do país. Entretanto, a divulgação do Censo 2010 reverteu tal tendência. Embora a população de indígenas como um todo tenha aumento no país, ainda que em ritmo mais lento do que na década anterior, houve uma diminuição dos indígenas recenseados em áreas urbanas. Com isso, o grau de urbanização da população indígena passou de 52\% para 39\%, entre 2000 e 2010.

Buscando exemplificar as oscilações no volume de indígenas captado pelos censos recentes, observa-se que o total de indígenas no país aumentou 2, 5 vezes entre os Censos de 1991 e 2000, sendo que nas áreas urbanas essa ampliação foi de 5,4 vezes no período. Contudo, o mesmo crescimento não se repetiu na década seguinte. Divulgados os resultados do Censo Demográfico de 2010, verificou-se aumento de $11 \%$ do total de indígenas no Brasil em relação a 2000 , sendo que nas áreas urbanas houve redução de $18 \%$ do total de indígenas captados (Tabela 1).

TABELA 1

Indígenas, segundo situação de domicílio

Brasil - 1991-2010

\begin{tabular}{lccc}
\hline Situação do domicílio & $\mathbf{1 9 9 1}$ & $\mathbf{2 0 0 0}$ & $\mathbf{2 0 1 0}$ \\
\hline Urbano & 71.026 & 383.298 & 315.180 \\
Rural & 223.105 & 350.829 & 502.783 \\
Total & 294.131 & 734.127 & 817.963 \\
\hline
\end{tabular}

Fonte: IBGE. Censos Demográficos 1991, 2000, 2010.

As variações recentes da captação da cor ou raça da população têm sido creditadas, principalmente, à subjetividade da pergunta do censo e às mudanças no processo de construção de identidade racial e reconhecimento étnico (CARVALHO; WOOD; ANDRADE, 2003; PERZ; WARREM; KENNEDY, 2008; DIAS JÚNIOR et al., 2009). Pouco se sabe, contudo, sobre o impacto do desenho dos questionários e dos formatos das entrevistas nos resultados da operação censitária. 


\section{Aspectos comparativos entre os Censos de 2000 e 2010}

Os censos demográficos brasileiros mantêm uma elevada consistência temática entre as operações, permitindo acompanhar as transformações experimentadas pela população brasileira ao longo de décadas e, assim, conhecer sua dinâmica demográfica de longo prazo. Em que pese o cuidado para garantir que os resultados dos censos sejam comparáveis entre si, os procedimentos de campo, processamento e crítica das informações têm sofrido modificações ao longo dos anos, visando, segundo o IBGE, aprimorar os processos de coleta. Nesse sentido, os censos tendem a incorporar os avanços tecnológicos disponíveis na época de sua realização. Foi assim com a introdução dos cartões perfurados no Censo de 1940, o leitor digital dos questionários no Censo 2000 e a completa informatização da coleta do Censo 2010. Esse foi primeiro censo brasileiro a abandonar completamente o questionário em papel.

Segundo o IBGE (s/d):

Para alcançar os melhores padrões de qualidade no Censo 2010, o IBGE introduziu várias inovações gerenciais, metodológicas e tecnológicas, com destaque para a atualização da base territorial digital, a adoção do computador de mão equipado com GPS para a coleta dos dados, a introdução da internet como alternativa para preenchimento do questionário e a informatização dos cerca de 7000 postos de coleta instalados pelo IBGE para gerenciar o Censo 2010 em todos os 5565 municípios brasileiros.

A informatização completa da operação em 2010 possibilitou inúmeras alterações de conteúdo e desenho do questionário, sendo uma delas especialmente importante para a presente discussão: a alteração na forma de realização da entrevista. A implementação do questionário digital permitiu que o formato de "entrevista individual”, utilizado em 1991 e 2000, passasse para o formato "em bloco" em 2010. Desse modo, em vez de realizar todas as perguntas para um morador do domicílio e, em seguida, realizar as perguntas para os moradores subsequentes, um de cada vez, passou-se a fazer cada pergunta para todos os moradores ao mesmo tempo.

Segundo o IBGE (2016, p. 449):

Uma novidade do questionário na Internet, que posteriormente foi adaptada para o questionário no computador de mão, foi a possibilidade de preenchimento dos dados de vários moradores simultaneamente, ou seja, o morador podia responder a mesma pergunta para todos os outros simultaneamente, ganhando tempo e praticidade.

Acredita-se que as alterações no formato das entrevistas tenham trazido ganhos operacionais para a realização da operação de coleta. Por outro lado, conforme a hipótese defendida no presente ensaio - que dialoga com estudos que realizaram análises similares -, esse tipo de mudança no formato da entrevista favorece a generalização das informações pelo respondente para todos os moradores do domicílio (BARROS et al., 2013; HESS et al., 2011). Tal fato teria levado à redução da diversidade intradomiciliar de algumas características dos moradores, incluindo as informações de cor ou raça indígena. 
Barros et al. (2013) avaliaram o impacto da mudança no formato das entrevistas do Censo Demográfico de 2010 em relação aos censos anteriores e a outras pesquisas domiciliares realizadas pelo IBGE. Incorporando quatro categorias de variáveis em seu estudo, os autores apresentam evidências de associação da passagem de entrevistas individuais para entrevistas em bloco e uma homogeneização dos domicílios do Brasil.

Os autores realizaram comparações entre os Censos de 1980, 1991, 2000 e 2010 para os quesitos de cor ou raça, local de nascimento, religião e alfabetização. Como essas questões também constavam nas Pesquisas Nacionais por Amostragem de Domicílios (PNADs) realizadas nesse período e nas Pesquisas de Orçamentos Familiares (POFs) produzidas em $2002 / 2003$ e 2007/2008, seus resultados foram incorporados à análise visando contornar possíveis particularidades da operação censitária.

Segundo os autores, o formato de entrevistas realizadas em bloco favorece respostas do tipo "todos aqui são brancos" ou "ninguém aqui migrou”, por exemplo. 0 estudo mostra que os resultados do Censo 2010 inverteram a tendência observada na série histórica dos censos e contradisseram a tendência reportada nas POFs e PNADs.

Em relação à variável cor ou raça, os autores observaram que para todos os domicílios com pelo menos dois moradores havia uma tendência de queda dos percentuais de domicílios em que todos os moradores tinham a mesma cor ou raça, passando de $72,4 \%$ em 1980 para 62,3\% em 2000. Revertendo tal tendência, no Censo 2010 houve um ligeiro aumento neste percentual, atingindo $63,2 \%$ dos domicílios. Os resultados das PNADs e POFs analisadas também apontavam na direção de um aumento na diversidade dentro dos domicílios, revertida em 2010.

Em relação à variável de naturalidade no município, Barros et al. (2013) identificaram que havia uma diminuição do percentual de domicílios com a mesma resposta para todos os moradores entre 1980 e 2000, tendência que também se inverteu no Censo de 2010, quando esse percentual passou de $44,3 \%$ para $51,8 \%$ de domicílios com as mesmas respostas para todos os moradores.

Os resultados para religião apontam para a mesma direção: entre 1980 e 2000 houve uma queda no percentual de domicílios cujas respostas foram iguais para todos os residentes, passando de $90,8 \%$ para $78,8 \%$ nesses censos, respectivamente. Novamente, os dados de 2010 reverteram a tendência, registrando ligeiro aumento no percentual de domicílios em que todos os moradores declararam a mesma religião (80,0\% dos domicílios).

Por fim, em relação ao quesito sobre analfabetismo, que investiga se os moradores sabiam ler e escrever, o percentual de domicílios com respostas iguais teve aumento muito acima da média entre 2000 e 2010, principalmente naqueles com maior número de moradores, tendência oposta à evolução observada nas PNADs analisadas.

Buscamos, na próxima seção, realizar uma comparação entre os resultados dos últimos levantamentos censitários com foco na composição dos domicílios com indígenas no Brasil. 


\section{Perfis de domicílios com indígenas no Brasil}

No intuito de testar se a mudança no formato da entrevista pode ter tido impacto na composição dos domicílios em que residiam indígenas nos últimos censos, em termos de cor ou raça dos outros moradores, separamos os indígenas em dois grupos distintos: "domicílios homogêneos", em que todos os moradores eram indígenas; e "domicílios mistos", em que indígenas viviam com ao menos um indivíduo de outra cor ou raça. Tal procedimento é possível pois o IBGE divulga, em seus arquivos de microdados, informações tanto para indivíduos como para domicílios, mantendo uma variável que permite chavear as duas bases de dados (variável "controle"). Desse modo, podemos acompanhar as variações dos volumes de indígenas que residiam em domicílios em que todos os moradores eram indígenas, assim como dos domicílios multiétnicos (Tabela 2).

Em 1991, havia 91.193 domicílios onde residia pelo menos um indígena no Brasil. Esse número aumentou 3,5 vezes em 2000, chegando a 323.480 domicílios. Entre 2000 e 2010 , entretanto, houve redução de $13 \%$ dos domicílios com indígenas, que corresponderam a 280.380 .

A separação por tipo de domicílio em termos de composição por cor ou raça dos moradores mostra que a redução do número de domicílios com indígenas entre 2000 e 2010 deveu-se ao decréscimo de "domicílios mistos". Embora esse tipo de domicílio tenha aumentado quase 5 vezes entre 1991 e 2000, ele diminui $38 \%$ no segundo período da análise. Por outro lado, o número de “domicílios homogêneos” ampliou-se em todo período de análise, apesar de o crescimento ter sido menor entre 2000 e 2010 do que entre 1991 e 2000.

TABELA 2

Domicílios com indígenas, segundo situação e tipo do domicílio Brasil - 1991-2020

\begin{tabular}{|c|c|c|c|c|c|}
\hline \multirow{2}{*}{$\begin{array}{l}\text { Situação e tipo do } \\
\text { domicílio }\end{array}$} & \multirow{2}{*}{1991} & \multirow{2}{*}{2000} & \multirow{2}{*}{2010} & \multicolumn{2}{|c|}{ Variação (\%) } \\
\hline & & & & $1991-2000$ & $2000-2010$ \\
\hline \multicolumn{6}{|l|}{ Urbano } \\
\hline Homogêneo & 5.295 & 32.931 & 43.544 & 521,9 & 32,2 \\
\hline Misto & 37.460 & 207.446 & 131.825 & 453,8 & $-36,5$ \\
\hline Total & 42.755 & 240.377 & 175.369 & 462,2 & $-27,0$ \\
\hline \multicolumn{6}{|l|}{ Rural } \\
\hline Homogêneo & 35.465 & 49.155 & 87.251 & 38,6 & 77,5 \\
\hline Misto & 12.943 & 33.948 & 17.760 & 162,3 & $-47,7$ \\
\hline Total & 48.408 & 83.103 & 105.011 & 71,7 & 26,4 \\
\hline \multicolumn{6}{|l|}{ Total } \\
\hline Homogêneo & 40.760 & 82.086 & 130.795 & 101,4 & 59,3 \\
\hline Misto & 50.403 & 241.394 & 149.585 & 378,9 & $-38,0$ \\
\hline Total & 91.163 & 323.480 & 280.380 & 254,8 & $-13,3$ \\
\hline
\end{tabular}

Fonte: IBGE. Censos Demográficos, 1991, 2000, 2010.

Nota: Excluídos os domicílios com apenas um morador. 
A proporção de domicílios mistos apresentou discrepâncias entre as áreas urbanas e rurais: enquanto foi sempre superior a $75 \%$ dos domicílios com indígenas nas áreas urbanas nos três censos analisados, indicando tendência a multietnicidade domiciliar nesses espaços, nas áreas rurais alcançou média de apenas $28 \%$ nos três censos, com pico máximo de $41 \%$ em 2000 . Isso explica por que, mesmo tendo sido observada redução nos domicílios mistos em áreas urbanas e rurais entre 2000 e 2010, esse fenômeno levou à diminuição do total de domicílios captados - e consequentemente no total de indígenas - apenas nas áreas urbanas do país.

Complementando a análise, observa-se, a partir da Tabela 3, que a redução dos domicílios mistos foi mais acentuada entre aqueles com quatro ou mais moradores, tanto em áreas urbanas como rurais. Ou seja, o fenômeno concentrou-se nos domicílios maiores, em linha com as tendências apontadas por Barros et al. (2013), de associação entre aumento do tamanho do domicílio e sua homogeneização interna.

TABELA 3

Domicílios mistos com indígenas, segundo situação do domicílio e número total de moradores Brasil - 2000-2010

\begin{tabular}{|c|c|c|c|}
\hline $\begin{array}{l}\text { Situação do domicílio e número de } \\
\text { moradores }\end{array}$ & 2000 & 2010 & Variação (\%) \\
\hline \multicolumn{4}{|l|}{ Urbano } \\
\hline 2 moradores & 28.189 & 26.335 & $-6,6$ \\
\hline 3 moradores & 43.521 & 32.593 & $-25,1$ \\
\hline 4 moradores ou mais & 135.733 & 72.897 & $-46,3$ \\
\hline \multicolumn{4}{|l|}{ Rural } \\
\hline 2 moradores & 3.625 & 2.689 & $-25,8$ \\
\hline 3 moradores & 5.151 & 3.703 & $-28,1$ \\
\hline 4 moradores ou mais & 25.174 & 11.368 & $-54,8$ \\
\hline
\end{tabular}

Fonte: IBGE. Censos Demográficos 2000, 2010.

O processo de homogeneização das respostas do quesito também fez com que, embora tivesse havido uma redução dos percentuais de domicílios em que indígenas residiam com indivíduos de outras cores ou raças, ocorresse aumento concomitante dos domicílios homogêneos de indígenas. Isto é, não só indígenas desapareceram de domicílios multicolores, como indivíduos com outras cores ou raças sumiram dos domicílios indígenas.

No cômputo geral esse processo ainda manteve o crescimento do número de indígenas residentes nas áreas rurais, ainda que em menor ritmo do que na década anterior, ao passo que causou decréscimo entre aqueles que residiam em áreas urbanas.

Em termos das oscilações no volume de indivíduos captados pelos dois censos, o número de indígenas residentes em domicílios homogêneos passou de 344.581 em 2000 para 572.643 em 2010, com um aumento de $66,2 \%$. Já o número dos que residiam em domicílios mistos diminuiu 38,6\% no período, passando de 369.567 para 226.783 indígenas, no mesmo período. Não estão incluídos nessa comparação, obviamente, os indígenas que viviam sós em cada um dos censos. 
Para compreender o padrão espacial do fenômeno apresenta-se, na Tabela 4, a desagregação dos dados analisados segundo a região geográfica. Observa-se que, com exceção dos residentes nas áreas urbanas do Sudeste, houve aumento de indígenas residentes em domicílios homogêneos em todas as regiões do país, tanto para zonas urbanas como rurais. Por outro lado, houve redução dos indígenas residentes em domicílios mistos em todas as situações analisadas, inclusive em áreas rurais.

TABELA 4

Total de indígenas e variação, por tipo e situação do domicílio, segundo região geográfica Brasil - 2000-2010

\begin{tabular}{|c|c|c|c|c|c|c|c|}
\hline \multirow{3}{*}{$\begin{array}{l}\text { Região } \\
\text { geográfica }\end{array}$} & \multicolumn{2}{|c|}{ Indígenas } & \multicolumn{5}{|c|}{ Variação entre 2000 e 2010 por tipo de domicílio (\%) } \\
\hline & \multirow{2}{*}{2000} & \multirow{2}{*}{2010} & \multirow{2}{*}{ Total } & \multicolumn{2}{|c|}{ Homogêneo } & \multicolumn{2}{|c|}{ Misto } \\
\hline & & & & Urbano & Rural & Urbano & Rural \\
\hline Centro-Oeste & 101.988 & 127.345 & 24,9 & 50,6 & 56,0 & $-26,8$ & $-56,8$ \\
\hline Nordeste & 165.667 & 202.727 & 22,4 & 106,4 & 114,3 & $-24,6$ & $-35,2$ \\
\hline Norte & 211.311 & 302.168 & 43,0 & 131,4 & 64,5 & $-14,7$ & $-51,6$ \\
\hline Sudeste & 153.652 & 95.162 & $-38,1$ & $-4,9$ & 48,1 & $-49,5$ & $-64,1$ \\
\hline Sul & 81.530 & 72.024 & $-11,7$ & 3,7 & 48,6 & $-44,0$ & $-58,5$ \\
\hline Brasil & 714.148 & 799.426 & 11,9 & 60,6 & 67,7 & $-36,0$ & $-48,9$ \\
\hline
\end{tabular}

Fonte: IBGE. Censos Demográficos 2000, 2010.

Nota: Não estão incluídos os quantitativos de indígenas que viviam sós (domicílios unipessoais).

Foi realizada, ainda, uma comparação dos perfis dos indígenas que residiam em domicílios mistos em 2000 e 2010, segundo algumas características sociodemográficas, como idade, alfabetização, nível de instrução e relação com o responsável pelo domicílio. 0 intuito é compreender o impacto da diminuição dos residentes em domicílios mistos nos perfis de indígenas enumerados nos últimos dois censos (Tabela 5).

Os dados mostram que a distribuição etária dos indígenas residentes em domicílios mistos é parecida entre os censos, com um ligeiro envelhecimento dos indivíduos. Há também pouca alteração na relação com o responsável pelo domicílio, exceto pela elevação do percentual de responsáveis (de 32\% para 37\%, entre 2000 e 2010) e uma pequena redução dos filhos. Por fim, analisando a variável nível de instrução, ${ }^{1}$ pode-se perceber que os indígenas captados em 2010 eram mais escolarizados do que aqueles que residiam nessa condição de domicílio em 2000.

\footnotetext{
${ }^{1}$ Optou-se por utilizar o nivel de instrução da população de 25 anos ou mais devido à impossibilidade de se calcularem anos de estudo da população no Censo de 2010, dada a ausência da investigação sobre última série concluída para toda a população nesse Censo.
} 
TABELA 5

Distribuição dos indígenas residentes em domicílios mistos, segundo variáveis selecionadas Brasil - 2000-2010

\begin{tabular}{lrr} 
& & Em porcentagem \\
\hline \multicolumn{1}{c}{ Variáveis } & $\mathbf{2 0 0 0}$ & $\mathbf{2 0 1 0}$ \\
\hline Grupos de idade & 22,8 & 20,8 \\
0 a 14 anos & 67,7 & 67,8 \\
15 a 59 anos & 9,5 & 11,5 \\
60 anos ou mais & 100,0 & 100,0 \\
Total & & 37,5 \\
Relação com o responsável pelo domicílio & 32,6 & 21,2 \\
Pessoa responsável & 22,5 & 29,2 \\
Cônjuge, companheiro(a) & 33,0 & 11,2 \\
Filho(a), enteado(a) & 10,0 & 0,9 \\
Outro parente & 1,9 & 100,0 \\
Demais moradores & 100,0 & 8,3 \\
Total & & 43,4 \\
Escolaridade da população de 25 anos ou mais & 23,2 & 25,8 \\
Antigo primário & 27,5 & 9,6 \\
Ensino fundamental ou equivalente & 12,7 & 12,9 \\
Ensino médio ou equivalente & 3,4 & 100,0 \\
Ensino superior & 33,2 & 100,0 \\
Outros & & \\
Total & & \\
\hline
\end{tabular}

Fonte: IBGE. Censos Demográficos 2000, 2010

\section{Discussão}

As diferenças na captação da cor ou raça da população entre os diferentes censos demográficos normalmente são discutidas sob o prisma do comportamento demográfico dos grupos populacionais, assim como das varições nos processos de autoidentificação e reconhecimento étnico e racial ao longo do tempo. Entretanto, pouco se discute no Brasil a respeito dos impactos das mudanças na metodologia de coleta do censo sobre o resultado de cada operação. Essa ausência vai de encontro à deficiência apontada por Chor (2013, p. 1274), quando afirma que os estudos sobre desigualdades raciais no Brasil carecem de maior fundamentação "do ponto de vista conceitual e metodológico, assim como de discussões consistentes de seus resultados".

0 presente estudo analisou as diferenças no perfil domiciliar dos indígenas nos Censos de 2000 e 2010 segundo a composição étnico-racial dos moradores dos domicílios. As análises consideraram as regiões geográficas de residência, a situação urbana e rural do domicílio, além de alguns atributos individuais dos moradores. Os resultados mostram que houve uma diminuição do número de indígenas residentes com indivíduos de outras categorias de cor ou raça, ao mesmo tempo que ocorreu um aumento daqueles que viviam em domicílios homegêneos do ponto de vista étnico. Tal fato contradiz as tendências de 
aumento da miscigenação étnica intradomiciliar no Brasil, via uniões entre pessoas com diferentes cores ou raças (RIBEIRO; SILVA, 2009). Ainda que aceitemos que a explicação para o fenômeno seja multicausal, o fato de a variação ter ocorrido nitidametne entre os tipos de domicílios selecionados, simultaneamente à mudança no formato de realização das entrevistas de cada censo, indica que pode haver associação entre esses dois processos.

No Censo de 2010, por exemplo, as mães ou pais indígenas poderiam ter reportado com maior frequência aos seus filhos como indígenas em comparação com o Censo 2000, conforme destaca Marinho (2015). Isso certamente sofreu impacto de movimentos de ações afirmativas, das lutas do movimento indígena e de outros fatores que incentivaram a afirmação da identidade. Contudo, acreditamos que também tenha havido efeitos do fato de as informações sobre cor ou raça terem sido obtidas simultaneamente para todos moradores de cada domicílio em 2010. No Censo de 2000, as entrevistas eram realizadas de forma individual e os dados de cada morador só eram coletados após a finalização de todas as perguntas do morador anterior.

Estudos futuros poderão lançar nova luz sobre o fenômeno, principalmente se a metodologia de coleta do próximo censo repetir aquela aplicada em 2010. 0 momento da discussão é oportuno, uma vez que os preparativos para a coleta do próximo censo estão em curso, ainda que a data de sua realização esteja indefinida. A seriedade com que o tema vem sendo tratado no país força-nos, enquanto pesquisadores, a não medir esforços para conhecer a realidade étnica da população brasileira, assim como os impactos das metodologias de coleta em sua identificação.

\section{Referências}

ARRUTI, J. M. Presença indígena no Rio de Janeiro? Uma introdução. Revista do Arquivo Geral da Cidade do Rio de Janeiro, v. 16, p. 14-31, 2019.

BARROS, L. F. W.; MATOS, G. G.; CAMPOS, M. B.; BORGES, G. M. Assessment of drawing impacts of the questionnaire in Brazilian Census of 2010. In: WORLD STATISTICS CONGRESS, 59. Proceedings [...]. Hong Kong, 2013.

CAMPOS, M. B.; BORGES, G. M.; QUEIROZ, B. L. Diferenciais de mortalidade entre indígenas e não indígenas no Brasil com base no Censo Demográfico de 2010. Cadernos de Saúde Pública, v. 33, n. 5, p. 1-6, 2017.

CAMPOS, M. B.; ESTANISLAU, B. R. Demografia dos povos indígenas: os Censos Demográficos como ponto de vista. Revista Brasileira de Estudos de População, v. 33, n. 2, p. 441-449, 2016.

CAMPOS, M. B.; Damasceno, M. De quem estamos falando? Indígenas residentes no Rio de Janeiro segundo o Censo Demográfico de 2010. Revista do Arquivo Geral da Cidade do Rio de Janeiro, v. 1, p. 97-114, 2019.

CAMPOS, M. The average Brazilian and the census: a critical approach to the questionnaire building. In: IUSSP INTERNATIONAL SEMINAR ON REGISTERING AND COUNTING THE POPULATION: THE PRODUCTION AND EXPLORATION OF CENSUS INFORMATION FORM EARLY MODERN TIMES TO THE END OF THE 20TH CENTURY. Proceedings [...]. Campinas: Unicamp, 2016. 
CARDOSO DE OLIVEIRA, R. Urbanização e tribalismo: a integração dos índios Terêna numa sociedade de classes. Rio de Janeiro: Zahar Editores, 1968.

CARVALHO, J. A. M.; WOOD, C. H.; ANDRADE, F. C. D. Notas acerca das categorias de cor dos censos e sobre a classificação subjetiva de cor no Brasil: 1980/90. Revista Brasileira de Estudos de População, v. 20, n. 1, p. 29-42, 2003.

CHOR, D. Desigualdades em saúde no Brasil: é preciso ter raça. Cadernos de Saúde Pública, v. 29, n. 7, p. 1272-1275, 2013.

DIAS JÚNIOR, C. S.; VERONA, A. P.; PENA, J. L.; MACHADO-COELHO, G. L. L. Crescimento da população indígena em Minas Gerais: análise da influência da dinâmica demográfica e reclassificação racial a partir dos dados censitários de 1991-2000. Revista Brasileira em Promoção da Saúde, v. 22, p. 157-163, 2009.

HESS, J.; MOORE, J.; PASCALE, J.; ROTHGEB. J.; KEELEY, A. The effects of personal-level versus house-level questionnaire design on survey estimates and data quality. Public Opinion Quarterly, v. 65, n. 4, p. 574-84, 2001.

HORTA, C. Indígenas em Canarana: notas citadinas sobre a criatividade parque-xinguana. Revista Antropologia, v. 60, n. 1, p. 216-241, 2017.

IBGE - Instituto Brasileiro de Geografia e Estatística. 0 Censo Demográfico 2010. Rio de Janeiro, s/d. Disponível em https://sidra.ibge.gov.br/pesquisa/censo-demografico/demografico-2010/ inicial (acesso em outubro de 2020).

IBGE - Instituto Brasileiro de Geografia e Estatística. Metodologia do Censo Demográfico 2010 / IBGE. 2. ed. Rio de Janeiro: IBGE, 2016.

LONGO, L. A. F. B.; FERREIRA, L. O.; AZEVEDO, M. M. D. A. Nupcialidade indígena: possibilidades e limitações de análise utilizando os dados do Censo Demográfico de 2010. Revista Brasileira de Estudos de População, v. 33, n. 2, p. 375-398, 2016.

MAGNANI, J. G. C.; ANDRADE, J. A. A. D. Uma experiência de etnologia urbana: a presença indígena nas cidades da Amazônia. In: AMOROSO, M. R.; SANTOS, G. M. Paisagens ameríndias. Lugares, circuitos e modos de vida na Amazônia. São Paulo: Editora Terceiro Nome, 2013.

MUNIZ, J. O. Preto no branco? Mensuração, relevância e concordância classificatória no país da incerteza racial. Dados - Revista de Ciências Sociais, v. 55, n. 1, p. 251-282, 2012.

NUNES, E. S. Aldeias urbanas ou cidades indígenas? Reflexões sobre índios e cidades. Espaço Ameríndio, v. 4, n. 1, p. 9-30, 2010.

OLIVEIRA, J. P. O nascimento do Brasil e outros ensaios: "pacificação", regime tutelar e formação de alteridades. Rio de Janeiro: Contracapa, 2016.

PEREIRA, N. D. O. M. Avanços na captação de dados sobre a população indígena no Censo Demográfico 2010. Revista Brasileira de Estudos de População, v. 33, n. 2, p. 423-430, 2016.

RIBEIRO, C. A. C.; SILVA, N. V. Cor, educação e casamento: tendências da seletividade marital no Brasil, 1960 a 2000. Dados - Revista de Ciências Sociais, v. 52, n. 1, p. 7-51, 2009.

TEIXEIRA, P. Migração, urbanização e características da população indígena do Brasil através da análise dos dados censitários de 1991 e 2000. In: III CONGRESSO DE LA ASSOCIACION LATIOAMERICANA DE POBLACIÓN. Anais [...]. Córdoba: Alap, 2008.

TEIXEIRA, P.; MAINBOURG, E.; BRASIL, M. Migração do povo indígena Sateré Mawé em dois contextos urbanos distintos na Amazônia. Caderno CRH, v. 22, n. 57, p. 531-546, 2009. 
WONG, L. R. Tendências da fecundidade dos povos indígenas nos Censos Demográficos brasileiros de 1991 a 2010. Revista Brasileira de Estudos de População, v. 33, n. 2, p. 399-421, 2016.

MARINHO, G. L. Domicílios indígenas nos censos demográficos: classificação, composição e interfaces com a saúde. 2015. 156 f. Tese (Doutorado) - Escola Nacional de Saúde Pública Sergio Arouca, Fundação Oswaldo Cruz, Rio de Janeiro, 2015.

PERZ, S.; WARREN, J. W.; KENNEDY, D. P. Contributions of racial-ethnic reclassification and demographic processes to indigenous population resurgence: the case of Brazil. Latin American Research Review, v. 43, n. 2, p. 7-33, 2008.

WOOD, C. H.; CARVALHO, J. A. M. A demografia da desigualdade no Brasil. 27. ed. Rio de Janeiro: Ipea, v. 1, 1994.

\title{
Sobre 0 autor
}

Marden Campos é professor do Departamento de Sociologia e do Programa de Pós-Graduação em Sociologia da Universidade Federal de Minas Gerais (UFMG). Foi coordenador do Grupo de Trabalho Demografia Indígenas da Abep entre 2018 e 2020.

\section{Endereço para correspondência}

Universidade Federal de Minas Gerais, Faculdade de Filosofia e Ciências Humanas, sala 4166

Av. Presidente Antônio Carlos, 6627, Pampulha

31270-901 - Belo Horizonte-MG, Brasil

\begin{abstract}
Tell me who you live with and I'll tell you who you are: oscillations in the enumeration of indigenous people in Brazilian demographic censuses
\end{abstract}

Demographic censuses are an important source of information on the living conditions of indigenous peoples in Brazil. Different factors have been pointed out to explain the variations in the volume of indigenous people captured by the censuses, as well as fluctuations in their spatial distribution. These studies focus on analyses of the demographic dynamics of these populations, as well as the influence of the processes of identity recognition and self-determination in indigenous numbers. However, studies into the impact of the census methodology on the results found for indigenous people are unknown. This paper analyzes the results of the latest national censuses in Brazil for indigenous people according to their region of residence, household situation and household composition, indicating that changes in the format of interviews observed in the last two demographic censuses had an impact on the household profile of the indigenous people and, consequently, in the number of those registered in the country. This impact would even have led to a reduction in those who lived in urban areas.

Keywords: Indigenous peoples. Demographic census. Brazil. Questionnaires. 


\section{Resumen}

Dime con quién vives y te diré quién eres: oscilaciones en la enumeración de los pueblos indigenas en los censos demográficos brasileños

Los censos demográficos son una fuente importante de información sobre las condiciones de vida de los pueblos indígenas en Brasil. Se han señalado diferentes factores para explicar las variaciones en el volumen de indígenas capturados por los censos, así como las fluctuaciones en su distribución espacial. Estos estudios se enfocan en análisis de la dinámica demográfica de estas poblaciones, así como en la influencia de los procesos de reconocimiento de identidad y autodeterminación en la población indígena. Sin embargo, se desconocen los estudios que investigan el impacto de la metodología del censo en los resultados encontrados para los pueblos indígenas. Este trabajo analiza los resultados de los últimos censos nacionales en Brasil para los pueblos indígenas según su región de residencia, situación del hogar y composición del hogar, indicando que los cambios en el formato de las entrevistas observados en los dos últimos censos demográficos tuvieron un impacto en el perfil del hogar. de los pueblos indígenas y, en consecuencia, en el número de inscritos en el país. Este impacto incluso habría llevado a una reducción de quienes vivían en áreas urbanas.

Palabras clave: Indígena. Censo demográfico. Brasil. Cuestionarios.

Recebido para publicação em 04/01/2020

Aceito para publicação em 28/05/2021 